\title{
Correction to: Evaluating recycling fertilizers for tomato cultivation in hydroponics, and their impact on greenhouse gas emissions
}

\author{
Aladdin Halbert-Howard ${ }^{1} \cdot$ Franziska Häfner $^{1} \cdot$ Stefan Karlowsky $^{2} \cdot$ Dietmar Schwarz $^{2} \cdot$ Ariane Krause $^{1}$ (ib
}

Published online: 24 June 2021

(C) Springer-Verlag GmbH Germany, part of Springer Nature 2021

Correction to: Environmental Science and Pollution Research https://doi.org/10.1007/s11356-020-10461-4

This project has received funding from the European Union's Horizon 2020 research and innovation programme under grant agreement No 774233 .

Publisher's note Springer Nature remains neutral with regard to jurisdictional claims in published maps and institutional affiliations.

The online version of the original article can be found at https://doi.org/ 10.1007/s11356-020-10461-4

Ariane Krause

krause@igzev.de

1 "Next-generation horticultural systems" (HORTSYS), Leibniz

Institute of Vegetable and Ornamental Crops (IGZ) e.V,

Theodor-Echtermeyer-Weg 1, 14979 Großbeeren, Germany

2 "Functional Plant Biology" (FUNCT), Leibniz Institute of Vegetable and Ornamental Crops (IGZ) e.V, Theodor-Echtermeyer-Weg 1,

14979 Großbeeren, Germany 